\title{
“CENTOCHIESE": A HUNDRED CHURCHES IN ROME. AN ARCHIVAL PHOTOGRAMMETRIC PROJECT
}

\author{
G. Fangi ${ }^{* 1}$, C.Nardinocchi ${ }^{2}$, G.Rubeca ${ }^{2}$ \\ ${ }^{1}$ Ancona, Italia - gabriele.fangi@gmail.com \\ ${ }^{2}$ DICEA, Sapienza University of Rome, 00184 Roma, carla.nardinocchi@ uniroma1.it, gianluca.rubeca@ gmail.com
}

Commission II, WG II/8

KEY WORDS: Documentation, Churches, Data Base, Panorama, Spherical Photogrammetry

\begin{abstract}
:
Rome is the city where two different cultures have found their greatest architectural achievement, the Latin civilization and the Christian civilization. It is for this reason that in Rome there is the greatest concentration in the world of Roman buildings, monuments and Christian buildings and churches. Rome is the seat of the papacy; say the head of the Christian Church. Every religious order, every Christian nation has created its own headquarters in Rome, the most representative possible, as beautiful, magnificent as possible. The best artists, painters, sculptors, architects, have been called to Rome to create their masterpieces. This study describes the photogrammetric documentation of selected noteworthy churches in Rome. Spherical Photogrammetry is the technique used. The survey is limited to the facades only, being a very significant part of the monument and since no permission is necessary. In certain cases, also the church interior was documented. A total of 170 Churches were surveyed. The statistics that one can derive from such a large number is particularly meaningful. Rome is the ideal place to collect the largest possible number of such cases. This study was motivated by the desire to provide technicians, architects, engineers and students with a technique that is easy to use and accessible and to show the great potential of the used photogrammetric technique. This article is a prelude to a book where all the panoramas obtained will be presented and made available to a larger public. Guidelines and tools to plot the facades will also be made available.
\end{abstract}

\section{INTRODUCTION}

Given the increasing fragility of our cultural heritage, their detailed three-dimensional (3D) reconstruction is necessary for the future generations, for further analysis and interpretation, and eventually for their physical reconstruction. This is particularly applicable to Italy in view of its enormous heritage.

Metric documentation of our cultural heritage is nowadays performed mainly by terrestrial laser scanners (Guarnieri et al., 2017; Barber et al., 2001; Beraldin et al., 2005; Remondino et al., 2008) or image based techniques (Campana et. al., 2007, Bahshar et al., 2015). Among these latter dense matching is widely used (Zhihua et al. 2014, Esposito et al., 2015, Fritsch et al., 2015). Moreover, the use of UAV has enlarged their field of application (Murtyoso et al., 2017). Both methods, range or image based, produce a point cloud which needs further processing to filter outliers and extract significant information. An alternative method to document cultural heritage, whose benefit has been widely reported (Fangi 2007; Fangi 2009, Fangi 2015), is that of spherical photogrammetry. Hassani, F., (2015) presents a review of different technologies for cultural heritage documentation, and among these, spherical photogrammetry, focusing on their potential and constraints.

Here, we describe a project of photogrammetric documentation applying Spherical Photogrammetry (SP). The title of the project is "Centochiese", that is the survey of about 100 Roman Churches. The initial objective was to cover 100 examples, the most significant ones, however, the final total was 170 . The project has the dual objective of experimenting SP feasibility in terms of timing and of creating a large documentary collection. Rome is the ideal field for this purpose due to the sheer number of monuments and the excellent quality of the architecture. The survey was limited to the façades, because no permission to survey and publish is necessary. Furthermore, the façade is a very significant part of the monument. On the contrary, there are many technical and bureaucratic difficulties regarding the survey of interiors.

The shooting procedure is quite simple and fast: with three or more spherical panoramas, almost all the details of the façade are summarized. Their orientation permits plotting with subdecimetric precision.

This article is a prelude to a book where all the panoramas obtained will be presented and made available to a larger public. Guidelines and tools to plot the facades will also be made available.

We wanted to demonstrate the enormous, in our opinion, potential of the method, that is in a short time and with little expense document Italy's immense architectural heritage. We followed the $3 \times 3$ Cipa rules.

This study is not intended to be an exhaustive tourist guide of the Churches of Rome. There are already many such publications, for instance the Italian Touring Club Guide (TCI, 2004), used as a reference in the preparation of this study. Other significant books of Rome's Churches is that by Armellini (Armellini, M., 1887) describing all the Churches of Rome until the beginning of the twentieth century and the masterful work by Portoghesi on Baroque Rome (Portoghesi, P., 1995). In addition, Achille Pinelli (Brizzi et al., 1990) must make mention of the beautiful watercolours at the beginning of the nineteenth century (figure 1). Using Pinelli's watercolours it is possible to evaluate changes made in the meantime. For example, Figure 1 shows the Pantheon before and after the elimination of the two bell towers.

There are churches of all Catholic nations, France, Spain,

Germany, Poland, Portugal, Greece, Armenia, etc. Many

churches, most of them, have already undergone heavy alterations over the centuries, overlapping styles and styles. The biggest difficulties for the project have been the heavy traffic and above all the wild car parks.

\footnotetext{
* Corresponding author
} 


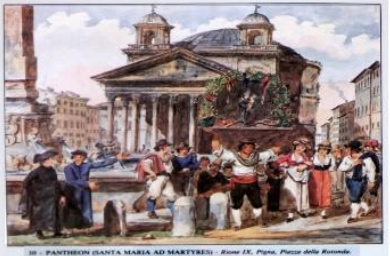

(a)

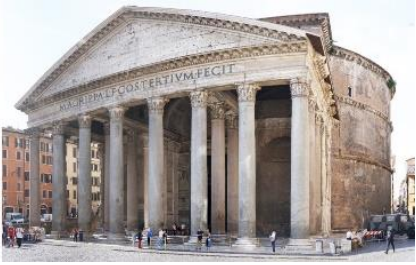

(b)
Figure 1. Pantheon. (a) Watercolour by Pinelli A., in the early 1800s. (b) Actual spherical panorama.

Next to the beautiful well-known masterpieces, some churches practically unknown were included, such as Santa Maria in Cappella, Santa Passera, Santa Agata dei Goti among others.

\section{A WALK THROUGH THE CHURCHES OF ROME}

Rome, with over 900 churches, holds the primacy of cities with the most churches in the world. Their history accompanies that of the capital for over seventeen centuries, a continual record of its religious, social and artistic evolution. Most of the churches are authentic masterpieces of architecture and history of art, concealing within paintings, sculptures and mosaics of inestimable value and represent not only for the citizens of Rome, but for the whole humanity, an invaluable, irreplaceable, unique heritage. Churches have very long and composite name to distinguish one from the other.

\subsection{Distinction by age}

It is impossible to summarize briefly centuries and centuries of the history of Rome churches. The earliest ones were built where Christians met privately or usually secretly. After the III century persecutions the Roman emperor Constantine I permitted the Christians to have their own place of worship. Then, over the centuries, the number of buildings used for religious worship grew exponentially, reaching their peak between the sixteenth and twentieth centuries.

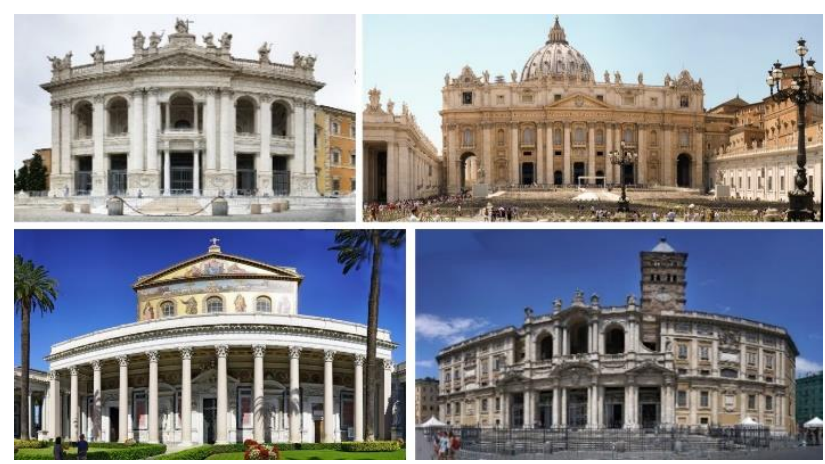

Figure 2- The four papal Basilicas; from top left clockwise: San Giovanni Laterano, San Pietro, Santa Maria Maggiore, San Paolo Outside the Wall.

Among the most important churches are the four papal Basilicas (figure 2), Archbasilica of St. John [in] Lateran , (that is the cathedral church of the Diocese of Rome), the Basilica of St. Peters in the Vatican, symbol of the Vatican state and commonly described as the largest in the world, the Basilica of St. Paul Outside the Walls and the Basilica of Santa Maria Maggiore. No less important are San Lorenzo Fuori le Mura (Outside the walls) and Santa Croce in Jerusalem (figure 3).

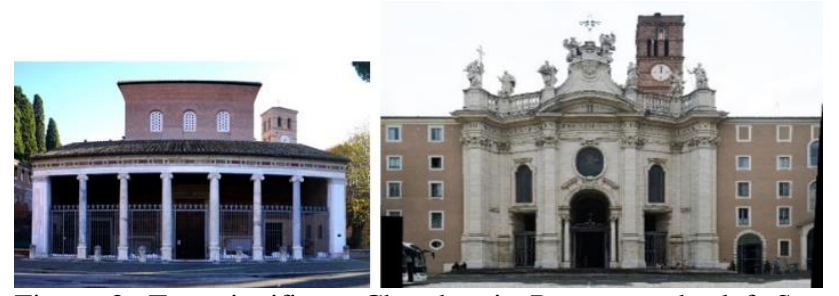

Figure 3- Two significant Churches in Rome: on the left San Lorenzo fuori le mura (Outside the Walls); on the right Santa Croce in Gerusalemme

About 300 churches date back to the 1700 s and more than half were selected for this study. Exceptionally a few twentieth century churches were included, such as Santa Maria della Consolazione in Tor Tre Teste, known as the Church of the Sails by Richard Meier in 2002. Figure 18 shows its 3D model

It is important to underline that these churches contain different historical layers, many of them, such as Santa Croce in Jerusalem, were built in the early Christian period, then subsequently adapted in the Romanesque and Baroque periods. Therefore, it is difficult to classify them as only belonging to one age.

Figure 4 shows church distribution according to epoch and style. They are grouped in 5 layers, the first from the III to IX century corresponding to the paleo Cristian age; from the $\mathrm{X}$ to XIV century the Romanic age; from the XV to XVI century the Renaissance; from the XVII to XVIII the Baroque style and finally the Neoclassic age from the XVIII to XX century.

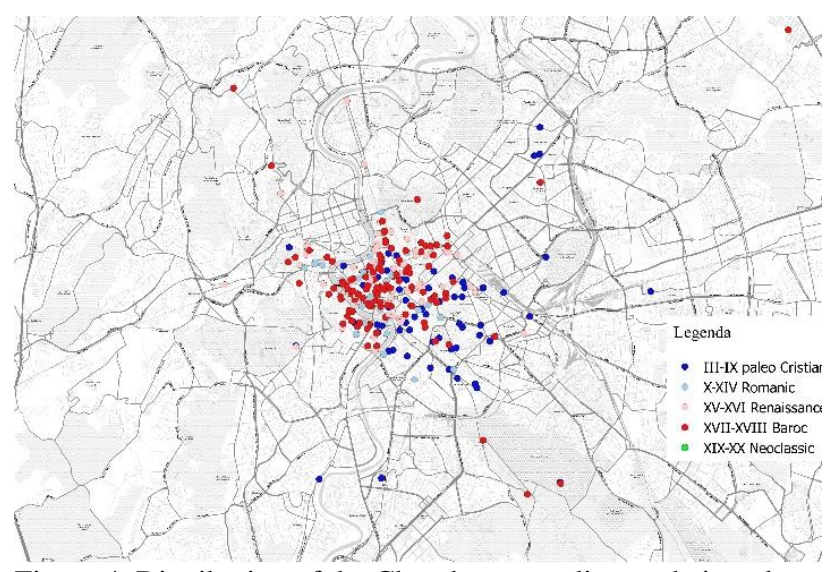

Figure 4. Distribution of the Churches according to their style.

\subsection{Classification by district}

Churches were classified into Rome's various districts. According to the Italian Touring Club Guide, (the only official guide recognized by the Ministry of Cultural Heritage), 11 districts (figure 4) listed below were identified: (1) Campitelli Sant'Angelo; (2) Campo Marzio-Colonna; (3) Castro Pretorio; (4) Celio; (5) Eustachio Pigna; (6) Mountains; (7) Quirinale; (8) Renaissance; (9) Ripa - Palatino; (10) Trastevere; (11) VaticanBorgo. In addition, those not included in these districts were classified as outside of Rome such as San Lorenzo Fuori le Mura (outside the walls). 


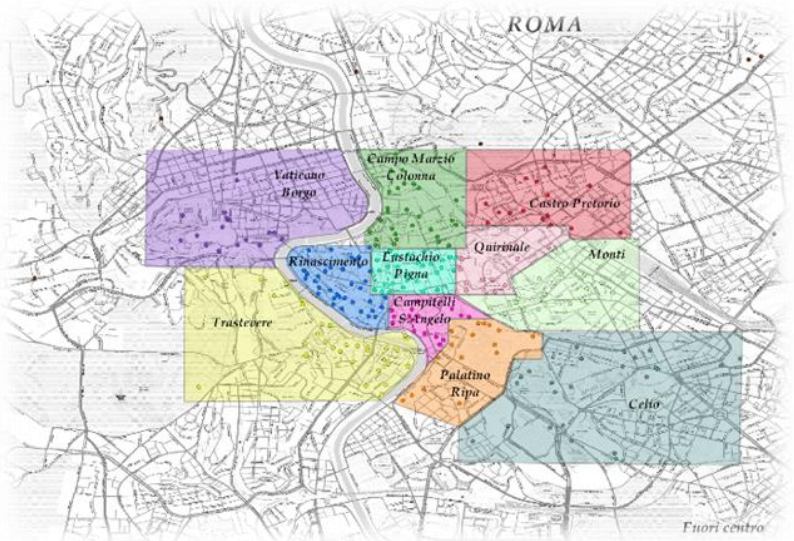

Figure 5. Map of the 11 districts.

Figure 5 provides a map of the districts distinguished by colour. For example, two maps of two different districts, Trastevere and Risorgimento, are shown respectively in Figure 6a and Figure 6b. The surveyed churches are depicted in green, and the others in red.

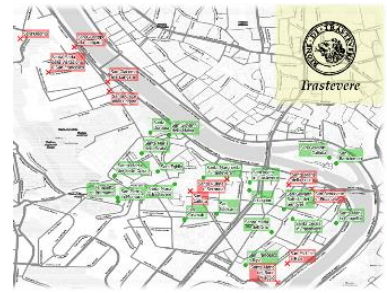

(a)

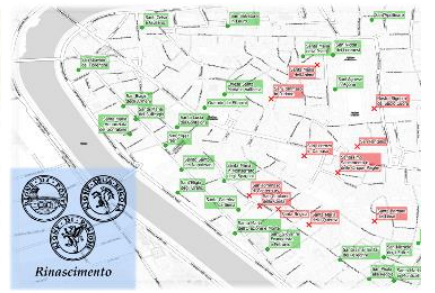

(b)
Figure 6. Map of a district. Surveyed churches in green. (a) District of Trastevere. (b) District of Rinascimento.

\subsection{The spherical panoramas}

A spherical panorama is an image with a wider field of view, up to $360^{\circ}$, and a much greater resolution than that of a single image. Practically, a panorama is an omnidirectional image which frees the operator from the constraint due to the fixed visual field of the traditional camera. Thus, a view similar to that of the human eye is produced, which permits a better understanding of the architectural structure. The panorama is itself an excellent tool for documentation, but is also a fast and rigorous survey method as widely demonstrated (Fangi, 2007, 2009, 2015), were the reader can find also details of the technique.

The facade panoramas were generated using the stitching technique by means of the PtGui ${ }^{\circledR}$ Version 10 software. The camera was in almost all cases, a full frame mirrorless Sony $\alpha 7$ RII, 40MB resolution, with a $35 \mathrm{~mm}$ fixed lens that can produce a $360^{\circ}$ panorama of $50,550 \times 25,250$ pixels, and few other projects a Canon Eos D450, 14 megapixel of resolution. For the purpose of this study, panoramas composed of 15-20 images with field of views less than $180^{\circ}$ were used. Figure 7 shows some of the facade panoramas.

Additionally, about 100 interior panoramas were also acquired with the Panono Camera (figure 8), an omni-camera built with 36 sensors (Escher, T., 2018). with a $360^{\circ} \mathrm{FOV}$ and a 16384 x 8192 pixels image resolution. Figure 9 shows the interior of Santa Passera Church. As an example of the omni-directionality of the panoramic image we show (figure 10) the zenith views of the church ceilings of Santissimo Sacramento or Oratorio dell'Angelo Custode and of San Bernardo alle Terme, obtained from the same panorama/images used for the plotting.
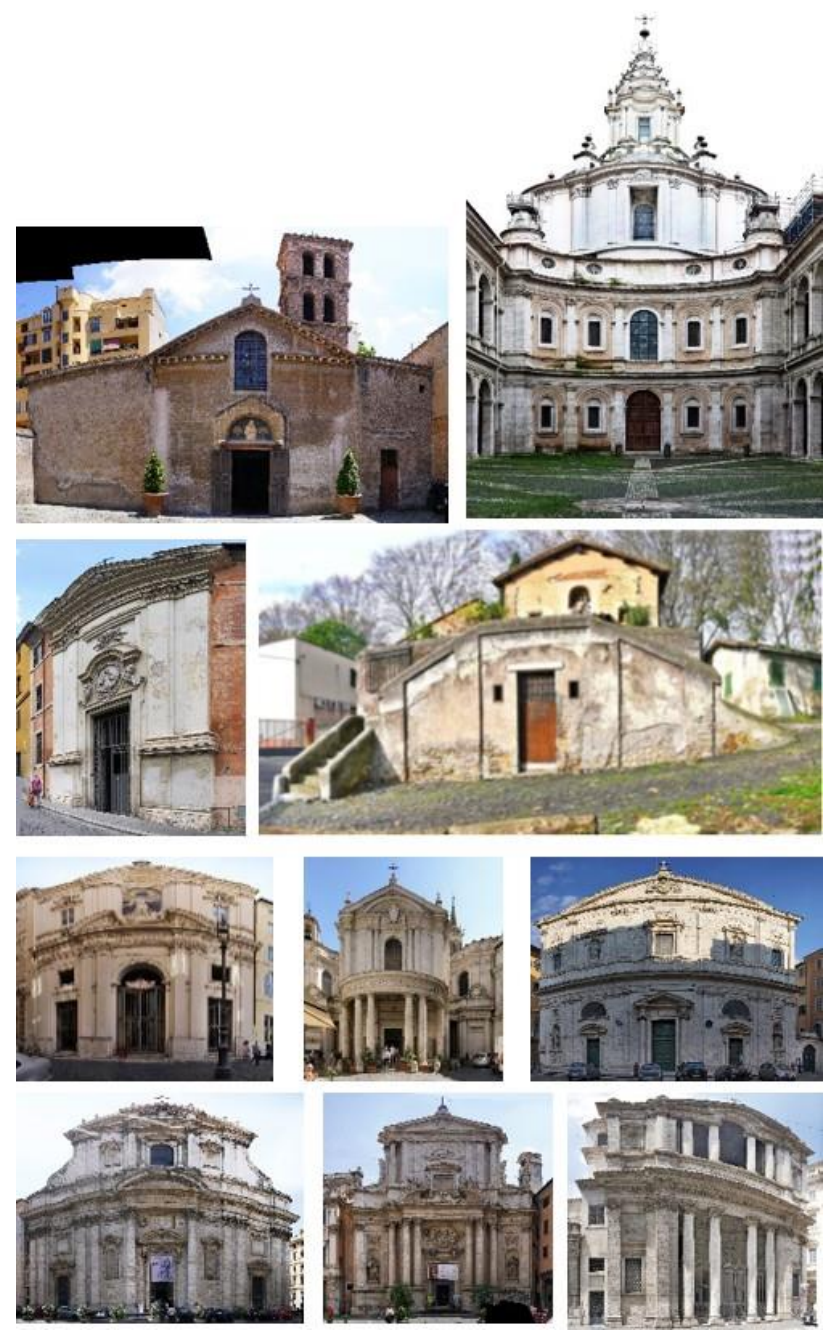

Figure 7 - Some of the facades panoramas. From left to right: in the first raw, Santa Maria in Cappella, Sant'Ivo alla Sapienza; in the second raw, Santa Agata dei Goti, Santa Passera; in the third raw, Santissime Stimmate di San Francesco, Santa Maria della Pace, S.Luigi dei Francesi; fourth raw, Sant'Ignazio, San Marcello al Corso, Santa Maria in Via.

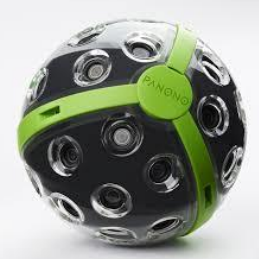

Figure 8. Panono Camera (www.panono.com)

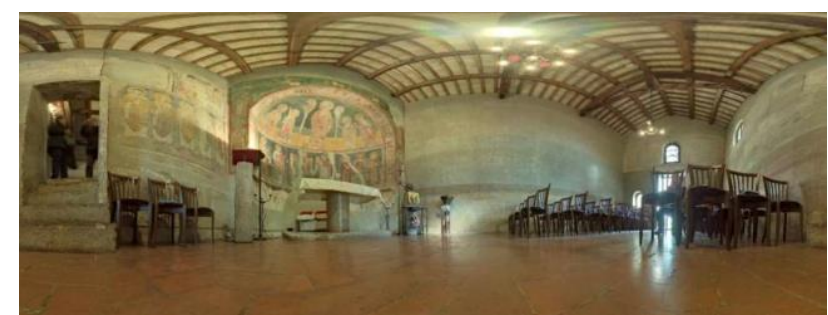

Figure 9- Santa Passera Church. A Panono panorama. 

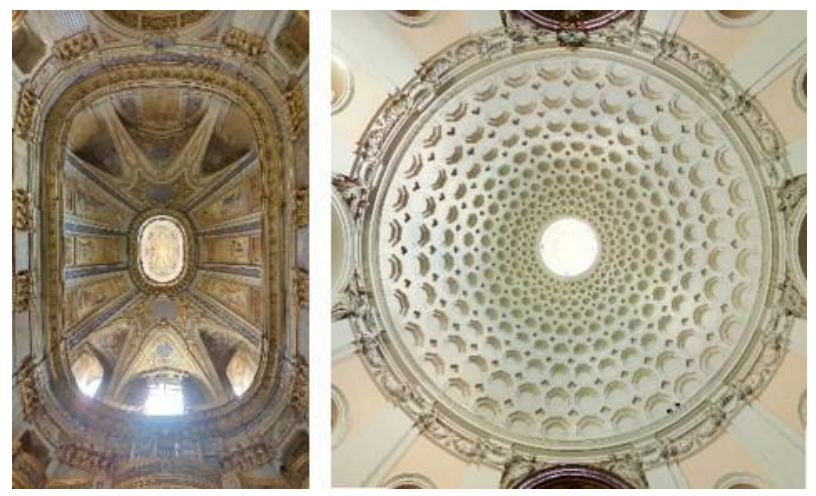

Figure 10- Zenith views of the ceiling of the churches of Santissimo Sacramento or Oratorio dell'Angelo Custode (on the left) and of San Bernardo alle Terme (on the right).

\section{SPERICAL PHOTOGRAMMETRY}

In this study 170 facades were surveyed in 4 measurement sessions, each consisting of 4 days. Average productivity was 10 12 churches a day. The equipment consisted of a tripod, in a digital camera and a panoramic head. Intentionally we did not want to use any special device such as lift arms or scaffolding, total stations or GPS. Targeting were also avoided.

The panoramas were produced with PtGui ${ }^{\circledR}$ version 10 software using the constrain of verticality of one or more lines. Therefore, "quasi-horizontal" panoramas characterized by two angles, roll and pitch, almost equal to zero (similar to a theodolite station) were obtained. Their image coordinates (row and column) can be easily converted (REF) in the angular values of the horizontal and vertical directions, scaled by a scale coefficient that is the radius of the virtual sphere. Once a minimum number of tie points are identified on all the panoramas of a façade a bundle adjustment process estimates the 6 orientation parameters for each panorama. Two ground control points (GCP) are used to fix the scale of the 3D model and when the distance of the two GCPs is the real one the $3 \mathrm{D}$ model is plotted in the real scale. Otherwise, the plotting in a CAD environment can be scaled later.

\subsection{The survey}

The survey of each church consists of taking pictures for the generation of the necessary panoramas. At least three panoramas are recommended, normally one in front of the facade and the other two by its left and right sides. In this study, usually 3 or 5 panoramas were used. Figure 11 summarizes the number of panoramas for each church, from a minimum of 3 to a maximum of 19 panoramas.

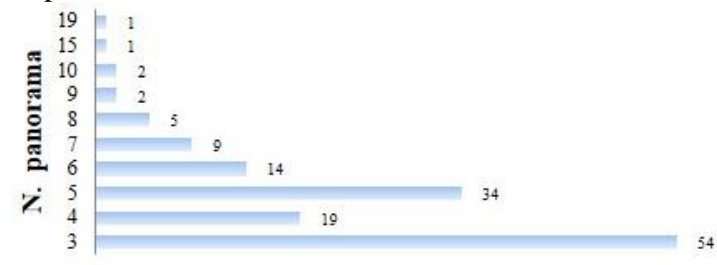

Figure 11. Number of panoramas per project.

A larger number of panoramas, up to a maximum of 19, were necessary in most complex situations such as San Paolo Fuori le Mura, or the Basilica of Santa Maria Maggiore

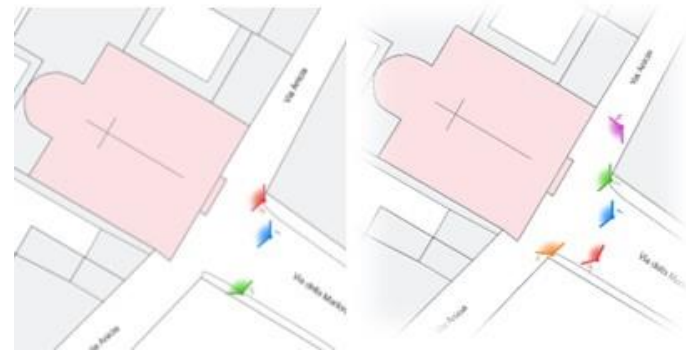

Figure 12 - S.Maria dell'Orto, configuration of three and five panoramas.

In general, a larger number of panoramas minimizes the occlusions, but many façades are so simple that do not require more than three such as those shown in figure 13. Moreover, in many other cases, it is the physical environment that does not permit more stations due to the lack of space. As an example, figure 12 shows the survey of Santa Maria dell'Orto where both configurations, with 3 and 5 panoramas, were used. Here we had a previous TLS survey to assess the survey quality (Figure 13). 40 points were extracted from the point cloud and a subdecimetric error (mean error of about 5 centimetre between the green points) was obtained with the largest error at the top greater than $20 \mathrm{~cm}$ on the 38 checkpoints considered.

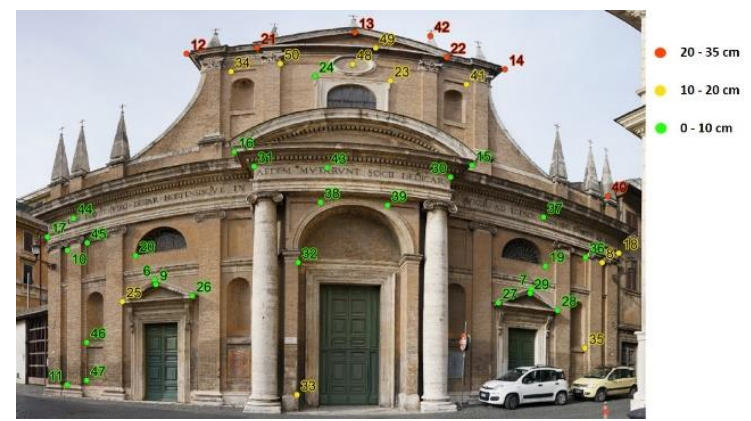

Figure 13 - Santa Maria dell'Orto

In this case the addition of two panoramas did not result in an improvement caused by the unfavourable configuration.

To obtain a ground pixel of about $2-3 \mathrm{~mm}$, the acquisition distance should be roughly equal to elevation of the façade. This is limited by site accessibility such as the width of the street.
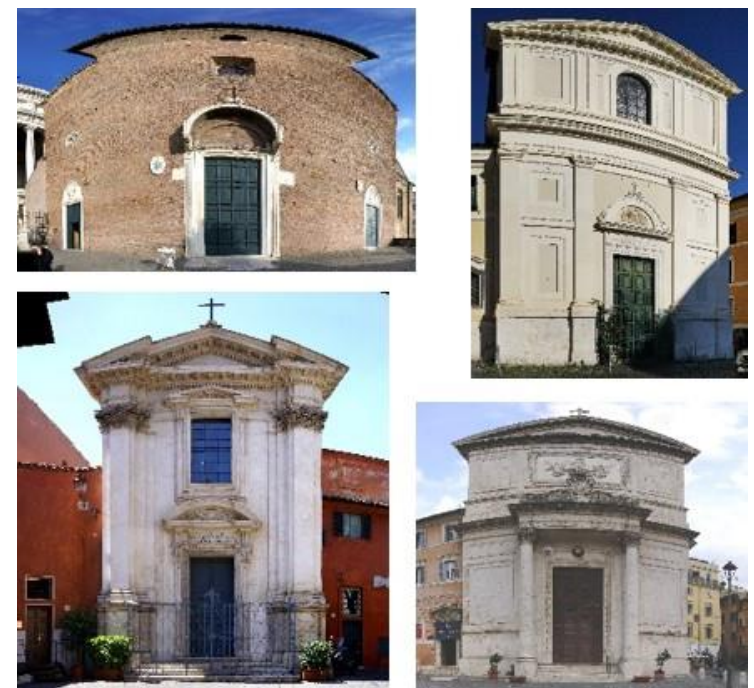

Figure 14 - Churches documented with three panoramas; from top left clockwise: Santa Maria in Aracoeli, San Giovanni dei Genovesi, San Salvatore in Lauro, Sant'Egidio. 
For some churches, such as Santa Passera, Sant'Andrea in Viale Tiziano, Le Vele by R.Meyer, S.Ivo alla Sapienza, we carried out a closed traverse around the building to permit the plot of the whole 3D model (figure 18, figure 19, figure 21).

\subsection{Orientation}

We performed the orientation with Sphera software (Fangi, 2009) after manual collimation of the tie points and the two ground control points. At least 5 tie points per project were used and in addition some geometrical constraints such as horizontal or vertical lines between this points were enforced. To date only 141 churches were oriented. Figure 14 shows the observations used to orientate the Church of Santa Maria dell'Orto in Trastevere.

The orientation process of Sphera software proceeds by successive steps (Fangi, Nardinocchi, 2013). First, a horizontal distance (two GCP) is set to a priori value or true value when known. Then, at least 5 tie points for a 3 panoramas project are collimated and some geometric constraints such as horizontal / vertical lines are added to overcome the system's lability.

Based on coplanarity condition at least one binocular or trinocular model is formed and successively all the formed models are linked and oriented by a triangulation with independent models.

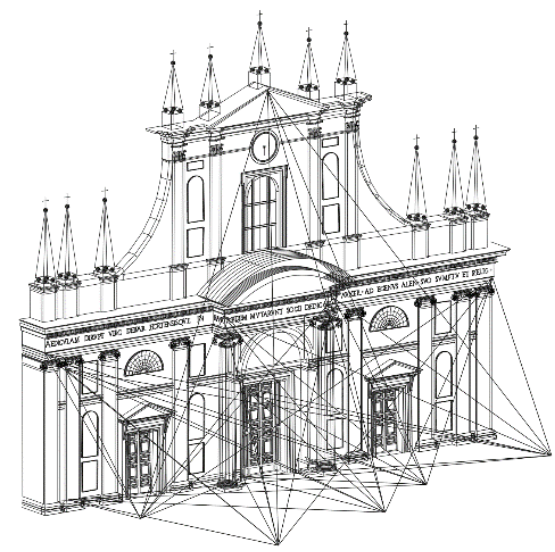

Figure 15 - S.Maria dell'Orto by Vignola (1566), the plot and the arrangement of the 5 panoramas (by G.Rubeca).

Approximate solution of panorama orientation is obtained by means of a bundle adjustment with 4 parameters per panorama ( 3 coordinates and the station bearing) assuming equal to zero the roll and pitch angles. The final solution at 6 parameters is obtained solving the bundle adjustment also considering pitch and roll angles corrections.

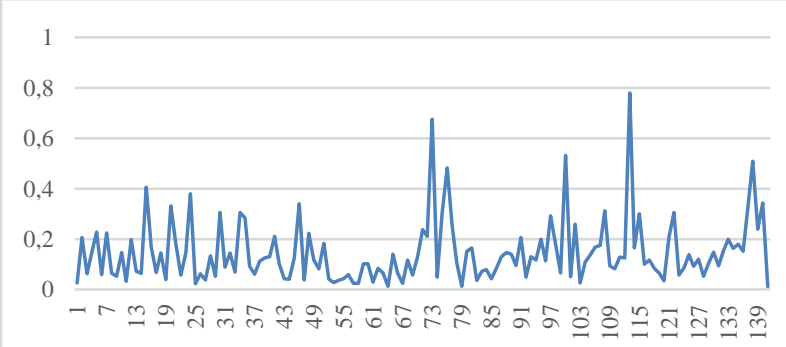

Figure 16 -Distribution of average standard deviation expressed in gons for all the 141 oriented churches.
The average standard deviation was 0.1457 gons ( 0.0023 radians) with a maximum value of 0.7795 pixels ( 0.0122 radians). Figure 16 shows the results of the average standard deviation for all the 141 churches. Higher values (larger than 0.4 gons) were obtained in only 5 projects. We observed that in such cases the configuration was very unfavourable the ratio distance/elevation of the façade being very small.

\begin{tabular}{|l|c|c|c|r|}
\hline & \multicolumn{2}{|c|}{ BA 4 parameters } & \multicolumn{2}{c|}{ BA 6 parameters } \\
\hline & $\sigma_{0}(\mathrm{rad})$ & $\sigma_{0}(\mathrm{rad})$ & $\sigma_{0}(\mathrm{rad})$ & $\sigma_{0}$ (gons) \\
\hline Mean & 0.00399 & 0.25418 & 0.0023 & 0.1457 \\
\hline Min & 0.00032 & 0.02054 & 0.0002 & 0.0112 \\
\hline Max & 0.01515 & 0.96438 & 0.0122 & 0.7795 \\
\hline SD & 0.00292 & 0.18616 & 0.0020 & 0.1249 \\
\hline
\end{tabular}

Table 1. Average standard deviation for bundle adjustment at 4 and 6 parameters.

Table 1 compares the mean, maximum, minimum values and standard deviation of the average standard deviation obtained with the bundle adjustment at 4 and 6 parameters.

The introduction of the two correction angles, as expected, significantly improves the accuracy. The output of this step is a file containing the orientation parameters of all panoramas.

\subsection{Plotting}

The plotting is obtained with the interface of PointsRecord, which is a software interfaced with Sphera which obtains the ground coordinates of the collimated image points according to the relationship of spherical photogrammetry. Inputs are the panoramas and the orientation file (*.ori) which contains the 6 external orientation parameters of each panorama. Output are a $*$.dxf file and an asci file *.pnt with the terrain coordinates.

Below, the plots of three churches are shown: Santa Maria dell'Orto by Jacopo Barozzi, called Vignola (1566), 'Le Vele' by Richard Meier (2002) and the Sant'Ivo alla Sapienza by Francesco Borromini (1660). They are examples of very different architectures, each representative of their epoch.

The plotting generates a wireframe which can be modelled as in Figure 17 and 18, 21.

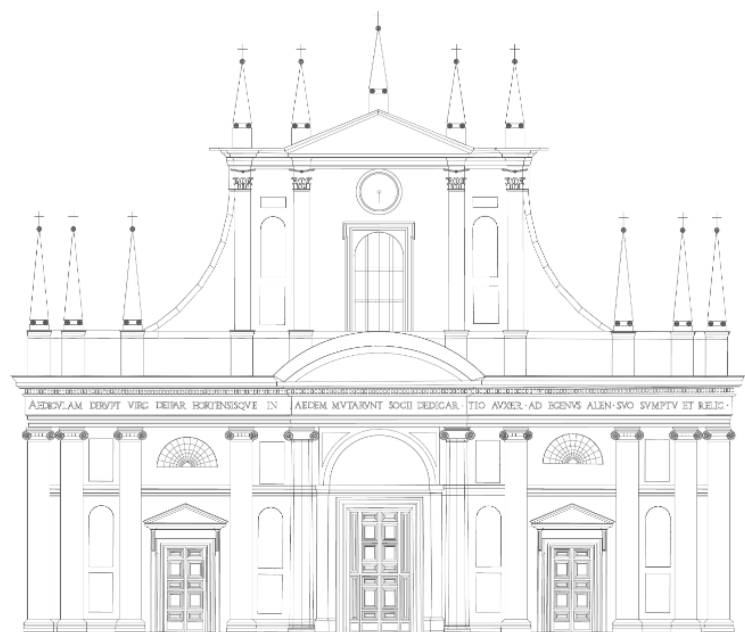

Figure 17 -S. Maria dell'Orto - the plot of the frontal view (plot by G. Rubeca). 


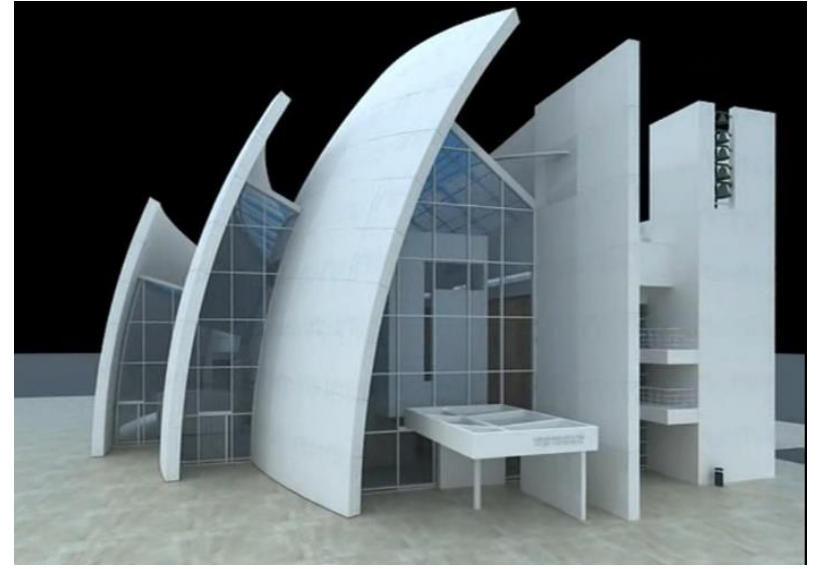

Figure 18. 3D Model of 'Le Vele' by Richard Meier in Tor Tre Teste (plot by T. Ortolani and S. Refi).

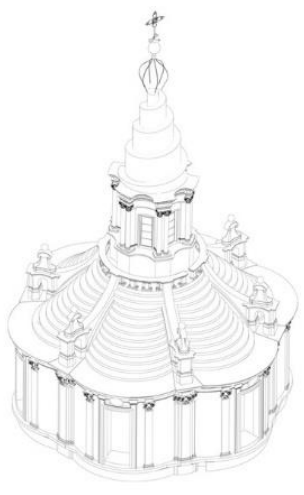

(a)

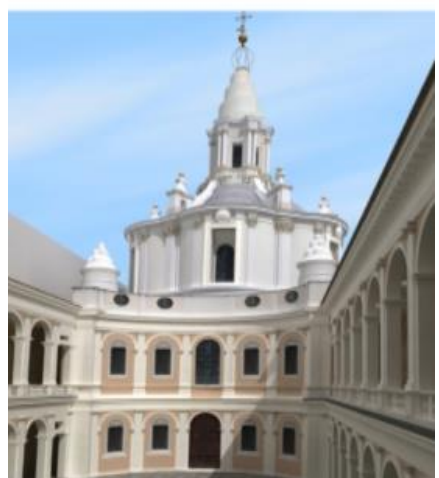

(b)
Figure 19. Sant'Ivo alla Sapienza. (a) Wireframe of the lantern; (b) Rendered 3D Model (plot by Chiara and Cecilia Manarini).

\section{CONCLUSIONS}

This study describes a project of photogrammetric documentation of some of the most notable facades of Rome's churches using Spherical Photogrammetry. The goal was to constitute an archive with the surveyed churches and make it available to plot later to anyone interested.

For each church the panoramas will be provided, as well as the correspondent orientation file and the output of the correspondent bundle adjustment project to furnish the statistical reference. In addition, the plotting software PointsRecord will be provided, too.

However, documentation, and more specifically, metric documentation is a very important assignment, especially for a city such as Rome with such a large cultural heritage. Many of the churches explored are off the traditional tourist route.

170 churches were surveyed and to date 141 oriented. Moreover, he interior of 20 churches was surveyed. The statistics derived from such a large number of cases is really meaningful. The average standard deviation is 0.1457 gons. The correction of the pitch and roll angles improved the accuracy of almost the half value, as expected. The principal problem in the present project was being able to carrying out the survey in optimal panorama configuration. In fact, worse results were obtained in narrow streets and high facades. Moreover, only a few churches in Rome have enough space around them to be able to perform a traditional image acquisition. Parked vehicles worsened the situation. Tourists who also flock to the more popular churches, hamper taking clean photographs. In almost all the projects it is possible to achieve sub-decimetrical accuracy.

To conclude, it is important to recall the fragility of much of our Italian cultural heritage, as shown by the collapse of the roof of San Giuseppe dei Falegnami despite its recent restauration. The church is also included in our project (figure 20), but unfortunately was not available, such as many others, for the internal survey because it was closed.

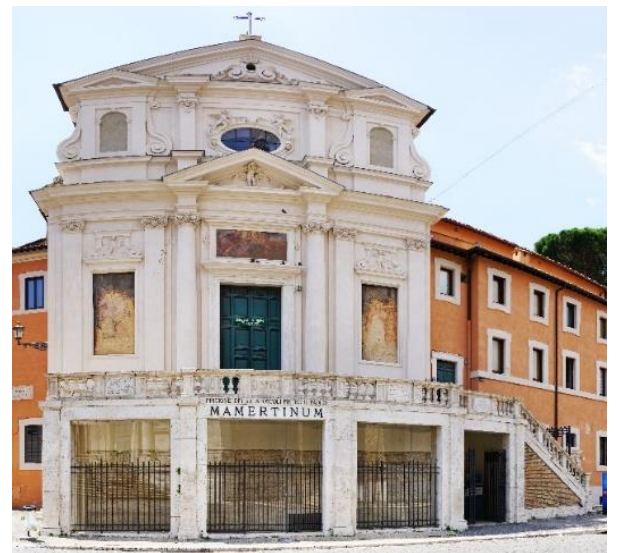

Figure 20. Spherical panorama of San Giuseppe dei Falegnami.

Why the present experience is not extended to all the churches not only in Rome, but even throughout Italy? It would be very cheap project and it can be carried out in a very short time, to realize a metric documentation, although not complete. The technique allows an efficient documentation of a good degree of precision.

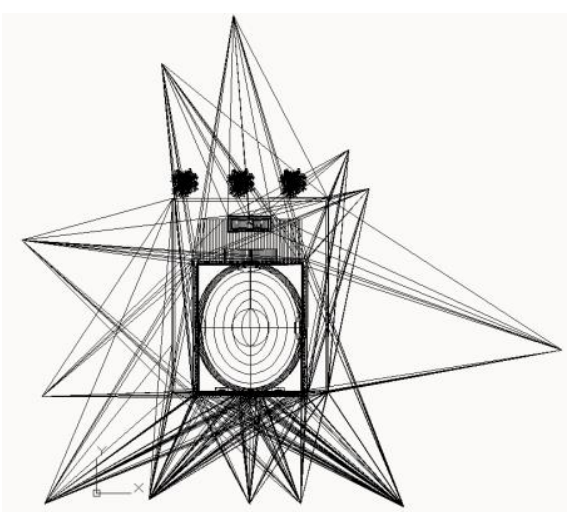

(a)

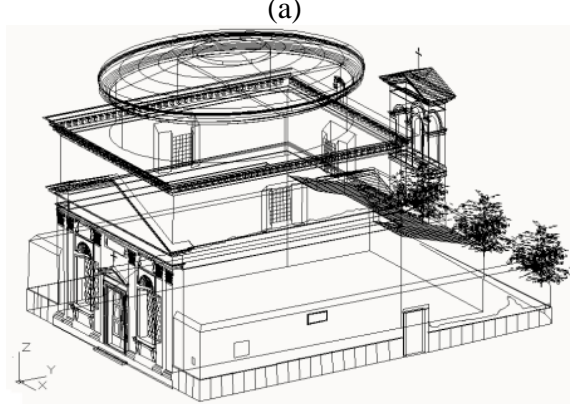

(b)

Figure 21 . Sant'Andrea in Tiziano alley by Vignola a) control network, the arrangment of the twelve panoramas, b) 3D model (plot by GL Rubeca ) 


\section{REFERENCES}

Armellini, M., 1887. Le Chiese di Roma dalle loro Origini sino al Secolo XVI. Tipografia Editrice Romana, via del Nazareno, 11, 1887.

Barber, D., Mills, J., Bryan, P.G., 2001. Laser scanning and photogrammetry-21th century metrology. In: ISPRS Archives of the Photogrammetry, Remote Sensing and Spatial Information Sciences, Vol. XXXIV-5/C7, XVIII CIPA Symposium, pp. 215222.

Bahsar, A., Gerke, M., Vosselmann, G., 2015. Efficient use of Video for 3D Modelling of Cultural Heritage Objects. In: ISPRS Annals of the Photogrammetry, Remote Sensing and Spatial Information Sciences, Vol. II-3/W4, 2015, PIA15+HRIGI15 Joint ISPRS conference 2015, 25-27 March 2015, Munich, Germany

Beraldin, J. A., Picard, M., El-Hakim, S., Godin, G., Borgeat, L., Blais, F., Paquet, E., Rioux, M., Valzano, V., Bandiera, A., 2005. Virtual reconstruction of heritage sites: opportunities and challenges created by 3D technologies. In: Proc. of the International Workshop on Recording, Modelling and Visualization of Cultural Heritage, Ascona, Switzerland. DOI: $10.1117 / 12.594226$

Brizzi, B., Barroero, L., Gallavotti Cavallero D., 1990. Le Chiese di Roma negli Acquerelli di Achille Pinelli, Colombo, Italia

Campana, S., Remondino, F., 2007. Fast and Detailed Digital Documentation of Archaeological Excavations and Heritage Artifacts. In: Proceedings of the $35^{\text {th }}$ International Conference on Computer Application and Quantitative Methods in Archaeology: Layers of Perception

Escher, T., 2018. Sperische Photogrammetrie mit der Panono Kamera.GIS Business, 4/2018. ISSN:1869-9286.

Esposito, S., Fallvollita, P., Wahbeh, W., Nardinocchi, C., Balsi, M., 2014. Performance evaluation of Uav Photogrammetric 3D Reconstruction. In: Geoscience and Remote Sensing Symposium (IGARSS), 2014 IEEE International: 4788-4791 Quebec, Canada, 13-18 July 2014. DOI: 10.1109/IGARSS.2014.6947565

Fangi, G., 2007. The multi-image spherical panoramas as a tool for architectural survey. In: International Archives of Photogrammetry, Remote Sensing and Spatial Information Sciences, Vol. XXXVI (5/C53), pp. 311-316.

Fangi, G., 2009. Further developments of the spherical photogrammetry for cultural heritage. In: XXII CIPA Symposium, Kyoto, Japan. 6 pages (on CD-ROM).

Fangi G., C., Nardinocchi, 2013. Photogrammetric Processing of Spherical Panoramas. In: Photogrammetric Record. 28(143): 293-311 (September 2013) DOI: 10.1111/phor.12031

Fangi, G., 2015. Towards an Easier Orientation for Spherical Photogrammetry. Int. Arch. Photogramm. In: ISPRS Archives of the Photogrammetry, Remote Sensing and Spatial Information Sciences, Vol. XL-5/W4, 279-283,2015. https://doi.org/10.5194/isprsarchives-XL-5-W4-279-2015

Fritsch, D.,Becker, S., Rothermel, M.,, 2013. Modeling facade structures using point clouds from dense image matching. In:
International Conference on Advances in Civil, Structural and Mechanical Engineering, 57-64

Hassani,F, 2015. Documentation of Cultural Heritage.

Techniques, Potentials and Constraints. In: ISPRS Archives of the Photogrammetry, Remote Sensing and Spatial Information Sciences, Vol. XL-5/W7, 2015

Naumann, M., Geist, M., Bill, R., Niemeyer, F., 2013. G.Grenzdörffer, Accuracy comparison of digital surface models created by unmanned aerial systems imagery and terrestrial laser scanner. In: ISPRS Archives of the Photogrammetry, Remote Sensing and Spatial Information Sciences, Volume XL-5/W2, 2013 XXIV International CIPA Symposium, 2 - 6 September 2013, Strasbourg, France.

Nocerino, E., Menna, F., Remondino, F., 2014. Accuracy of Typical Photogrammetric Networks in Cultural Heritage 3D Modeling Projects. In: ISPRS Archives of the Photogrammetry, Remote Sensing and Spatial Information Sciences, Volume XL5, Symposium, 23 - 25 June 2014, Riva del Garda, Italy

Portoghese, P., 1995. Roma Barocca. Collana Grandi Opere, ISBN: 9788842040408, Editrice Laterza

Remondino, F., Girardi, S., Gonzo, L., Rizzi, A., 2008. Multiresolution modeling of complex and detailed cultural heritage. In: Proc. of 9th Int. Symposium on Virtual Reality, Archaeology and Cultural Heritage (VAST 2008), Braga, Portugal, p 1-8. DOI: 10.1145/1551676.1551678

T.C.I., 2004. L'ITALIA, Roma. Touring s.r.l.

Zhihua, X., Lixin. W.,Yonglin, S., Fashuai L., Qiuling W., and Ran W., 2014. Tridimensional Reconstruction Applied to Cultural Heritage with the Use of Camera-Equipped UAV and Terrestrial Laser Scanner. In: Remote Sensing. 2014, 6, 1041310434; doi:10.3390/rs61110413. 